\title{
The Syndrome of Proximal Femur, Fibula and Midline Metatarsal Long Bone Deficiencies
}

\begin{tabular}{|r|l|}
\hline Journal: & Birth Defects Research \\
\hline Manuscript ID & Draft \\
\hline Wiley - Manuscript type: & Original Research Article \\
\hline Date Submitted by the Author: & n/a \\
\hline Complete List of Authors: & $\begin{array}{l}\text { Hootnick, David; State University of New York Upstate Medical University, } \\
\text { Vargesson, Neil; University of Aberdeen, School of Medicine, Medical } \\
\text { Sciences \& Nutrition }\end{array}$ \\
\hline Key Words: & $\begin{array}{l}\text { arterial transition, developmental growth failure, long bone deficiency, } \\
\text { proximal femoral focal deficiency, fibular deficiency, midline metatarsal } \\
\text { deficiency, dystrophism, post-specification errors }\end{array}$ \\
\hline \multicolumn{2}{|l}{} \\
\hline
\end{tabular}


SYNDROME OF LONG BONE DEFICIENCIES

Running Head: SYNDROME OF LONG BONE DEFICIENCIES

The Syndrome of Proximal Femur, Fibula and Midline Metatarsal Long Bone Deficiencies

David R. Hootnick, MD

SUNY Upstate Medical University, Syracuse, NY

Neil Vargesson, $\mathrm{PhD}$

University of Aberdeen

\begin{abstract}
Author Note:
David R. Hootnick, Departments of Orthopedic Surgery, Anatomy and Cell Biology and Pediatrics. SUNY Upstate Medical University, Syracuse, NY

Neil Vargesson, School of Medicine, Medical Sciences and Nutrition, Institute of Medical Sciences, University of Aberdeen, Foresthill, AB25-2ZD, Scotland
\end{abstract}

This paper is dedicated to the memory of our dear friend and colleague, David S. Packard, Jr, PhD, who originated the term 'post-specification error of limb development'. The authors also wish to thank Amy R. Slutzky, Phd, for bibliographic assistance and E. Mark Levinsohn, MD for deciphering the embryonic arteries, as described by Senior.

Correspondence concerning this article should be addressed to: David R. Hootnick, MD at Departments of Orthopedic Surgery, Anatomy and Cell Biology and Pediatrics, SUNY Upstate Medical University, 750 E. Adams St., Syracuse, NY 13210; Phone 315-464-5540; Email: hootnicd@upstate.edu; or prior to publication, to Cheryl Demers, Editorial Research Assistant. Email: cldemers@yahoo.com 
SYNDROME OF LONG BONE DEFICIENCIES

\begin{abstract}
Human lower extremity congenital long bone deficiencies cluster primarily at three distinct skeletal loci. Proximal femoral and fibular reductions are known phenomena. In contrast, midline metatarsal deficiencies have been misrepresented as lateral. The popular term, 'fibular hemimelia', is inaccurate and its use is discouraged.

All three loci correspond to discrete sites of evolving angiogenesis during transition from a single embryonic axial limb artery to the familiar and complex adult arterial pattern. Initiation of bone formation of cartilaginous primordia of the long bones at all three sites occurs in proximity to, and depends upon, successful invasion by mature nutrient vessels, formed during sixth and seventh weeks of embryonic development. The adult arterial pattern is fully established by eighth embryonic week.

Arterial transitions occur later in development, around the time of cessation of the molecular processes of patterning/specification of the embryonic limb. Evidence of flawed embryonic arterial transitions, involving missing, reduced and/or retained primitive vessels in association with congenital skeletal reductions have been demonstrated at all three loci.

Current molecular models of limb development do not explain the distribution of this triad of congenital skeletal reductions. Dysmorphologies are most accurately described as postspecification errors of limb development. Recognition of this distinctive model of limb maldevelopment demands further investigation to create a more exact taxonomy, one consistent with both clinical and molecular criteria. The established terminologies originated by Frantz and O'Rahilly should be abandoned. Designation of this clinical triad as a syndrome of proximal femur, fibula and midline metatarsal dystrophisms initiates that endeavor.
\end{abstract}


SYNDROME OF LONG BONE DEFICIENCIES

Key Words: arterial transition, developmental growth failure, dystrophism, long bone deficiency, proximal femoral focal deficiency, fibular deficiency, midline metatarsal deficiency, postspecification errors 
SYNDROME OF LONG BONE DEFICIENCIES

The Syndrome of Proximal Femur, Fibula and Midline Metatarsal Long Bone Deficiencies

Introduction

A recent radiographic review (Reyes, Birch, Hootnick, Cherkashin \& Samchukov, 2017)

reaffirms the accuracy of the assertion that, when metatarsal rays are missing in the feet of congenitally shortened limbs (CSL) with ipsilateral fibular deficiencies, the missing metatarsals are midline (Hootnick, Levinsohn \& Packard, 1980a). That premise, based on radiologic (Reyes et al, 2017; Hootnick et al., 1980a; Koczewski, Shadi, Kotwicki, Tomaszewski \& Korbel, 2013) and pathologic studies (Wagstaffe, 1873; Harmon \& Fahey, 1937; Arnold, 1959; Hootnick, Packard, Levinsohn, Lebowitz \& Lubicky, 1984), controverts an earlier, now presumably invalidated, supposition that the lateral border of the foot had been deleted from affected limbs in a 'fibular hemimelia' pattern. The term 'fibular hemimelia' has achieved a nearly universal acceptance over the past half century, without any scientific verification for that terminology (O’Rahilly, 1951; Frantz \& O’Rahilly, 1961; Spranger et al., 1982). Designation of the missing metatarsals as midline, in association with the previously acknowledged fibular deficiency, results in a distinctive nonlinear and noncontiguous combination of missing long bones.

Nomenclature of the CSL long bone reductions routinely utilize terms such as hypoplasia or dysplasia to describe the most affected long bone segments (Amstutz \& Wilson, 1962; Fixsen \& Lloyd-Roberts,1974; Hootnick, Boyd, Fixsen \& Lloyd-Roberts, 1977; Bohne \& Root, 1977). Analyses of tibial and femoral shortenings have taken precedence over the metatarsals, since the authors are primarily orthopedic surgeons, who treat leg length inequality (Hootnick et al., 1977; Menelaus, 1991; Song, Halliday \& Little, 1997). Ironically, the metatarsal reductions are usually 
SYNDROME OF LONG BONE DEFICIENCIES

the most obvious clinical deformity noted at birth but are considered of little consequence, because they require no surgical intervention (Stevens \& Arms, 2000).

A variety of the aforementioned long bone dysmorphologic features may coexist in the same limb in the varied forms of CSL. Labeling the CSL by its most deficient long bone skeletal structure simplifies the otherwise overwhelming complexities of the diverse constellation of alterations of an entire limb. The term 'fibular hemimelia' describes more than just an absent (sic) bone (Fordham, Applegate, Wilkes \& Chung, 1993; Grogan, Love \& Ogden, 1987). The named fibular deficiency is only a part of a dysplasia involving the entire limb (Arnold, 1959; Freund, 1936; Kruger \& Talbott, 1961; Hootnick, Levinsohn, Randall \& Packard, 1980b).

\section{Midline Metatarsal Deficiency}

Over the past century, the historical nomenclature(s) of lower extremity congenital skeletal reduction defects have been descriptive (O'Rahilly, 1951; Freund, 1936; Kruger et al., 1961; Hootnick et al., 1980a; Ollerenshaw, 1925). Nosology has been based upon the radiographic appearance of the long bones of juvenile limbs (O'Rahilly, 1951; Bedoya et al., 2015), while the soft tissues have been comparatively neglected. When the fibular shaft has been deficient, ipsilateral metatarsal ray deficiencies have also been casually designated as fibular sided (lateral) (O’Rahilly, 1951; Frantz et al., 1961).

Feet manifesting fewer than the normal complement of five metatarsals (44 to $84 \%$ ) (Thompson, Straub \& Arnold, 1957; Rodriguez-Ramirez, Thacker, Becerra, Riddle \& MacKenzie, 2010; Birch, Lincoln, Mack \& Birch, 2011) have been clinically and radiographically identifiable in congenitally shortened limbs (CSL) exhibiting fibular deficiencies (Reyes et al., 2017; Achterman, \& Kalamchi, 1979). Isolated metatarsal reductions 
SYNDROME OF LONG BONE DEFICIENCIES

have also been identified in the feet of limbs with features of apparent congenital shortening despite radiographically normal fibulae (Searle, Hildebrand, Lester \& Caskey, 2004; Baek, Kim, Chung \& Lee, 2008). An inverse relationship between leg length discrepancy and the absence of metatarsal rays has been observed: the more normal the foot, the greater the (femoral) shortening (Kruger et al., 1961; Rodriguez-Ramirez et al., 2010).

Many of the aforementioned long bone dysmorphologies may coexist in the varied forms of CSL. As fibular hemimelia is more than just an absent (sic) bone (Fordham et al., 1999; Grogan et al., 1987) but, rather, is part of a dysplasia of the entire limb, midline metatarsal reduction has been documented to occur in more than 50\% of CSL (Thompson et al., 1957; Rodriguez-Ramirez et al., 2010; Birch et al., 2011). Birch et al. (Birch et al., 2011) proposed a classification of limbs with fibular deficiency taking into account the functionality of affected feet, partially based on a 'preservability' parameter of three metatarsal rays; and secondly, according to the total limb length inequality.

\section{Fibular Deficiency}

Congenital absence of the fibula was first documented over three centuries ago by Goller (Coventry \& Johnson, 1952). It has continued to be the most frequent long bone deficiency described in orthopedic literature, occurring variously at 1 in 1,000 births (O'Rahilly, 1951; Ollerenshaw, 1925) to lower incidences of 0.004-0.02/1000 9 (Fordham et al., 1999) or 0.012/1,000 births (Holmes, 2011) in different series. The most popular orthopedic classification of congenital fibular deficiency encompasses a radiographic spectrum of three fundamental units of fibular dysmorphism: thinned, shortened or absent (Achterman et al., 1979). 


\section{SYNDROME OF LONG BONE DEFICIENCIES}

The characteristically "anomalous limb” (Arnold, 1959) featuring fibular deficiency displays alterations of the entire lower limb to a variable degree (O'Rahilly, 1951; Freund, 1936; Kruger et al., 1961). Fluid combinations of the CSL, which involve congenital fibular deficiency, may also include variable simple shortenings of the femur, tibia and/or fibula, proximal femoral focal deficiency (PFFD), coxa vara, lateral femoral condyle underdevelopment, absence of the cruciate ligaments, patellar underdevelopment, tibial bowing, a ball and socket ankle joint, tarsal coalitions, reduction of the number of metatarsal rays, equinovarus or equinovalgus foot deformity and Achilles tendon shortening (Freund, 1936; Ollerenshaw, 1925; RodriguezRamirez et al., 2010). Although limb length inequality has commanded the spotlight, the alignment and stability of the ipsilateral hip, knee and ankle have also merited scrutiny (Stevens, 2000).

Congenital reductions of the fibula and the proximal portion of the femur (PFFD) are strongly associated (Freund, 1936; Bedoya et al., 2015). Freund (Freund, 1936) opined that as a rule, congenital defects of the fibula and femur may not be classified individually, as the most recognized associated features of the radiographic spectrum of CSL limb anomalies. A strong association between the fibular and PFFD reductions has been observed in more than $45 \%$ of limbs of patients exhibiting either unilateral or bilateral PFFD (Koman, Meyer \& Warren, 1982). In addition, approximately half of CSL with fibular deficiency exhibit a reduced number of metatarsals (Reyes et al., 2017; Thompson et al., 1957; Rodriquez-Ramirez et al., 2010; Birch et al., 2011). The more severe fibular shortening has been associated with more reduced metatarsal ray numbers (Rodriquez-Ramirez et al., 2010; Birch et al., 2011). Birch (Birch et al., 2011) notably classified limbs with fibular deficiency according to functionality, partially based on the 
SYNDROME OF LONG BONE DEFICIENCIES

'preservability' parameter of feet with three rays; and secondly, on the total limb length inequality.

Several authors have ascribed the association of PFFD and fibular deficiency to a hypothesis of an undefined error in the patterning of limb bud development (Stevens et al., 2000; Lewin, \& Opitz, 1986). However, such imputed mechanisms have proven inconsistent not only with the detailed molecular mechanisms regarding the formation of the original limb model (Tabin \& Wolpert, 2007; Zuniga, Zeller \& Probst, 2012; Zuniga, 2015), but also with the distinctive pattern described herein.

\section{Femoral Deficiency}

Congenital deficiencies of the femur range from simple shortening to more localized, severe deficiencies of the femoral head, acetabulum and femoral shaft. The most widely cited classification by Aitken (Aitken, 1969) is based on morphology, as assessed by roentgenographic features. Proximal femoral focal deficiencies (PFFD) are defined as congenital skeletal limb deficiencies involving the proximal end of the femur, and, in most instances, the iliofemoral joint. Accordingly, all substantial congenital deficiencies of the proximal femur have subsequently been designated under the rubric of 'PFFD'. The criteria for inclusion as 'PFFD' in these classifications depends upon the following features: delay in appearance of the capital femoral epiphysis, alteration of the shape of the femoral head, the timing of appearance of the femoral neck, stunting or tapering of the proximal ends of the femoral shaft and late ossification of rudimentary cartilaginous femora.

The anatomic deficiencies have been further graded from a mild degree of femoral hypoplasia to subtotal absence of the femur (Amstutz et al., 1962). Classification (Hamanishi, 
SYNDROME OF LONG BONE DEFICIENCIES

1980) of the affected femora has varied according to the severity of the deficiencies of development of the proximal femoral anatomy. The classifications require alteration depending upon variations of the progression of femoral ossification that occurs with growth. A portion of the femur is always present, even when only a small distal fragment of the femur is shortened. In cases where the femoral head or the connection of the femoral head to the femoral shaft is not visualized via plain radiography, magnetic resonance imaging may allow visualization of the anatomy of the cartilaginous anlage of the femur (Bedoya et al., 2015).

Abnormalities of the contralateral lower extremity occur in $26 \%$ of patients, and of the ipsilateral fibula, in $50 \%$ of limbs. Bilateral deformity of the femur occurs in $10-15 \%$ of patients (Boden, Fallon, Deavidson, Mennuti \& Kaplan, 1989). Associated congenital defects of the lower extremity are found in more than $50 \%$ of patients with PFFD. The most common association with PFFD is ipsilateral fibular deficiency, which has been reported in as many of $80 \%$ of PFFD limbs (Bedoya, et al., 2015).

An inverse relationship, which exists between the severity of the reduction defects of the femora and the feet, has been confirmed repeatedly (Kruger et al., 1961; Rodriquez-Ramirez et al., 2010; Pappas, 1983). The more abnormal the foot, the less severe is the femoral shortening. Kruger and Talbott first pointed out that, in the limbs of those children with an essentially normal foot with five metatarsal rays, the femoral growth discrepancy usually is greatest, appears earliest, seems to increase most rapidly and is associated with the greatest ipsilateral shortening (Kruger et al., 1961).

Vascular Injury as a Mechanism for Embryonic Bone Loss and Developmental Growth Failure Development 
SYNDROME OF LONG BONE DEFICIENCIES

Human lower limb initial long bone skeletal development proceeds from primordial anlagen (German: foundations) during arterial transitioning, characterized by overlapping waves of angiogenesis progressing concurrently after the fifth week of embryonic development (Levinsohn, Hootnick \& Packard, 1991; Senior, 1919a, Senior, 1919b). The arterial transitions terminate by the eighth week. There are several periods of very rapid growth (Vargesson \& Hootnick, 2017). During those times, while the outgrowth of the lower extremities is rapidly progressing and after specification of the limbs nears termination, embryonic arterial alterations of the lower extremity evolves.

Since the critical period for the initiation of long bone development, beginning as mesenchymal condensations, occurs subsequent to the fifth week of embryonic life, during the time that the adult arterial pattern of vessels is emerging, the arterial and skeletal systems both may then be vulnerable to teratogenic insults. Maldevelopment of specific long bones and corresponding anomalous embryonic arteries may thus be intimately related.

The critical time for connection between the femoral artery and the sciatic (ischiadic) artery in the femoral region of the lower extremity is estimated to occur between the $12 \mathrm{~mm}$ and $14 \mathrm{~mm}$ stages of embryonic development (approximately week six) (Senior, 1919a, Senior, 1919b; Chomiak, Horak, Masek, Frydrychova \& Dungl, 2009). The critical time for arterial changes of the more distal part of the lower extremity in the tibial and fibular regions is estimated to occur between the $19 \mathrm{~mm}$ and $22 \mathrm{~mm}$ stages of embryonic development (approximately week seven) (Hootnick, et al., 1980b; Senior, 1919a).

Congenital arterial anomalies have been independently reported as associated with an asymmetric, noncontiguous pattern of congenital femoral (Chomiak et al., 2009), fibular (Hootnick et al., 1980b; Bedoya et al., 2015; Huda et al., 2014) and midline metatarsal (Hootnick 
SYNDROME OF LONG BONE DEFICIENCIES

et al., 1980a; Hootnick, Packard \& Levinsohn, 1983; Hootnick, 2014) long bone deficiencies.

The skeletal pathologies are manifested by dysmorphic bony patterns, which, interestingly, correspond closely to the embryonic arterial in-growth pattern of the late embryonic limb, ascribed to Senior (Senior, 1919a; Senior, 1919b; Senior, 1985). Associated deficiencies of development of proper nutrient arteries, associated with retained embryonic arterial patterns, correspond to a proposed syndromic prototypical pattern of long bone reductions of the femur (profunda femoris artery) (Hootnick et al., 1983), fibula (peroneal artery) (Hootnick et al., 1980b; Bedoya et al., 2015; Huda et al., 2014) and midline metatarsals (medial deep plantar arterial arch) (Hootnick et al., 1980a; Levinsohn et al., 1991; Hootnick et al., 1983; Sarrafian \& Kelikian, 2011).

\section{Conclusions}

The location of the missing metatarsals to a central/midline location (Reyes et al., 2017; Koczewski et al., 2013; Hootnick et al., 1980a) in association with other strongly associated lower extremity fibular and proximal femoral deficiencies suggests that a categorization of the primary combination of midline metatarsal, fibular and PFFD long bone deficiencies is warranted as the prototypical pattern of skeletal long bone reductions, among the wide variety of lower extremity long bone dysmorphologies (Hootnick, 2014).

Since the lateral foot tarsal cuboid and metatarsal foot structures have been shown to be normal in affected feet of CSL (Reyes et al., 2017; Hootnick et al., 1980a; Koczewski et al., 2013; Wagstaffe, 1973; Harmon et al., 1937), the current universally accepted term for the congenital fibular deficiency condition, fibula hemimelia (O'Rahilly, 1951; Frantz et al., 1961; Spranger et al., 1982; Bedoya et al., 2015) should be discouraged from use. Furthermore, this 
SYNDROME OF LONG BONE DEFICIENCIES

proposed syndrome of lower extremity long bone skeletal reductions is not consistent with the detailed molecular mechanisms which have been proposed to explain the formation of the original limb model (Tabin et al, 2007; Zuniga et al., 2012; Zuniga, 2015).

There has not been any historical awareness of any fundamental relationship among these otherwise anatomically distinct congenital long bone reductions, nor has there yet been any satisfactory systematic explanation for the seemingly fluid variety of skeletal long bone dysmorphologies. Although previously proposed molecular mechanisms may support some of the commonly observed limb reductions, such as those involving only the fibula (Tabin et al., 2007; Zuniga et al., 2012; Zuniga, 2015), such mechanisms do not encompass central metatarsal reduction in association with the fibular and proximal femoral bony deficiencies (Hootnick, 2014).

These congenital limb malformations, which constitute a majority of lower extremity birth defects, may thus be interpreted as post-specification events (Packard, Levinsohn \& Hootnick, 1991; Packard, Levinsohn \& Hootnick, 1993). This means that the dysmorphologies unfold after the primordia of the bony elements have been specified; but then become damaged, diminished or radiologically absent through failure or loss of appropriate vascularization resulting in diminished or (radiographically) missing bones.

An inverse relationship of femoral/foot midline metatarsal deficiencies are comprehensible as the result of independent teratogenic events due to asynchronous timings of distinct femoral and plantar arterial dysgeneses leading to the asymmetric dysmorphologies. Contrariwise, conforming fibular and metatarsal deficiencies suggest synchronous arterial reductions of the fibula and metatarsals (Hootnick et al., 1980a; Levinsohn et al., 1991; Sarrafian et al., 2011). 
SYNDROME OF LONG BONE DEFICIENCIES

Failure of embryonic arterial invasion to vascularize the condensing cartilage precursors of the involved long bones may result in the loss or reduction in the size of the primordia of the proximal femoral, fibular or metatarsal long bone anlagen. Given that the arterial transitions and invasions occur only after the future bones have been specified and are starting to condense, the damage occurs after (post)-specification.

The identification of arterial anomalies which occur after the specification of a normal limb model necessitates consideration of these events (Packard et al., 1991; Packard et al., 1993):

1. The arteries appear early in the limb at about the same time that the cartilaginous models of the bones are forming.

2. The vast majority of human limbs present with bony malformations also present a consistently abnormal arterial pattern.

3. The anatomy of the arterial anomaly stands out from all the other soft tissue anomalies.

From these facts, one concludes that an etiologically significant relationship exists between the development of the bony and arterial abnormalities. Thus, the teratogenic events leading to many of the malformations described above may be vascular in nature (Packard et al., 1991, Packard et al., 1993).

There has been little progress in the identification of the cause(s) of the majority of birth defects, despite the completion of the genome project over a decade ago. Since the patterns of lower extremity congenital long bone deficiencies, described herein, consistently occur in concert, they merit the status of a syndrome.

Recognition of this syndrome of deficiencies of the proximal femur, fibula and midline metatarsals may lead to advances in the taxonomy of lower limb skeletal defects. Coordinated clinical (Maroteaux \& LeMerrer, 1997) and molecular (Lenz, 1969) inquiries of this proposed 
SYNDROME OF LONG BONE DEFICIENCIES

vascular mediated post-specification mechanism may prove auspicious in achieving the elusive goal of understanding the genesis of such congenital limb dysmorphologies. 
SYNDROME OF LONG BONE DEFICIENCIES

\section{References}

Achterman, C., Kalamchi, A. (1979). Congenital deficiency of the fibula. J Bone Joint Surg Br, 61-B, 133-137. doi:10.1302/0301-620x.61b2.438260

Aitken, G.T. (1969). Proximal femoral focal deficiency: Definition, classification and management. In: Aitken G.T. ed. Proximal Femoral Focal Deficiency: A Congenital Anomaly. Washington, DC: National Academy of Sciences. p.1-22. Amstutz, H.C., Wilson P.D.,Jr. (1962). Dysgenesis of the proximal femur (coxa vara) and its surgical management. J Bone Joint Surg Am, 44-A, 1-24. doi:10.2106/00004623-19624401000001

Arnold, W.D. (1959). Congenital absence of the fibula. Clinical Orthopaedics, 14, 20-29. Baek, G.H., Kim, J.K., Chung, M.S., Lee, S.K. (2008). Terminal hemimelia of the lower extremity: Absent lateral ray and a normal fibula. Int Orthop, 32, 263-267. doi:10.1007/s00264006-0293-6

Bedoya, M.A., Chauvin, N.A., Jaramillo, D., Davidson, R., Horn, B.D., Ho-Fung, V. (2015). Common patterns of congenital lower extremity shortening: Diagnosis, classification, and follow-up. Radiographics, 35, 1191-1207. doi: 10.1148/rg.2015140196

Birch, J.G., Lincoln, T.L., Mack, P.W., Birch, C.M. (2011). Congenital fibular deficiency: a review of thirty years' experience at one institution and a proposed classification system based on clinical deformity. J Bone Joint Surg Am, 93, 1144-1151. doi: 10.2106/JBJS.J.00683

Boden, S.D., Fallon, M.D., Davidson, R., Mennuti, M.T., Kaplan, F.S. (1989). Proximal femoral focal deficiency. Evidence for a defect in proliferation and maturation of chondrocytes. J Bone Joint Surg Am, 71, 1119-1129. doi:10.2106/00004623-198971080-00001 
SYNDROME OF LONG BONE DEFICIENCIES

Bohne, W.H., Root, L. (1977). Hypoplasia of the fibula. Clin Orthop Relat Res, (125), 107-112. doi:10.1097/00003086-197706000-00016

Chomiak, J., Horak, M., Masek, M., Frydrychova, M., Dungl, P. (2009). Computed tomographic angiography in proximal femoral focal deficiency. J Bone Joint Surg Am, 91, 1954-1964. doi: 10.2106/JBJS.H.00902

Coventry, M.B., Johnson, Jr. E.W. (1952). Congenital absence of the fibula. J Bone Joint Surg Am, 34-A, 941-955. doi:10.2106/00004623-195234040-00021

Fixsen, J., Lloyd-Roberts, G. (1974). The natural history and early treatment of proximal femoral dysplasia. J Bone Joint Surg Br, 56, 86-95.

Fordham, L.A., Applegate, K.E., Wilkes, D.C., Chung, C.J. (1999). Fibular hemimelia: more than just an absent bone. Semin Musculoskelet Radiol, 3, 227-237. doi:10.1055/s-2008-1080068

Frantz, C.H., O'Rahilly, R. (1961). Congenital skeletal limb deficiencies. J Bone Joint Surg Am, 43-A,1202-1224. doi:10.2106/00004623-196143080-00012

Freund, E. (1936). Congenital defects of femur, fibula and tibia. Arch Surg, 33, 349-391. doi:10.1001/archsurg.1936.01190030002001

Grogan, D.P., Love, S.M., Ogden, J.A. (1987). Congenital malformations of the lower extremities. Orthop Clin North Am, 18, 537-554.

Hamanishi, C. (1980). Congenital short femur. Clinical, genetic and epidemiological comparison of the naturally occurring condition with that caused by thalidomide. J Bone Joint Surg Br, 62-B, 307-320. doi:10.1302/0301-620x.62b3.7410462 
SYNDROME OF LONG BONE DEFICIENCIES

Harmon, P.H., Fahey, J.J. (1937). The syndrome of congenital absence of the fibula. Surg Gynecol Obstet, 64, 876-887.

Holmes, L.B. (2012). Common Malformations: New York: Oxford Press, Inc.

Hootnick, D., Boyd, N.A., Fixsen, J.A., Lloyd-Roberts, G.C. (1977). The natural history and management of congenital short tibia with dysplasia or absence of the fibula: a preliminary report. J Bone Joint Surg Br, 59-B, 267-271. doi:10.1302/0301-620x.59b3.893503

Hootnick, D.R., Levinsohn, E.M., Packard, Jr., D.S. (1980a). Midline metatarsal dysplasia associated with absent fibula. Clin Orthop Relat Res, (150), 203-206. doi:10.1097/00003086198007000-00034

Hootnick, D.R., Levinsohn, E.M., Randall, P.A., Packard, Jr., D.S. (1980b). Vascular dysgenesis associated with skeletal dysplasia of the lower limb. J Bone Joint Surg Am, 62, 1123-1129. doi:10.2106/00004623-198062070-00009

Hootnick, D.R., Packard, Jr., D.S., Levinsohn, E.M. (1983). Congenital tibial aplasia with polydactyly: implications of arterial anatomy for abnormal limb morphogenesis. Prog Clin Biol Res, 110 Pt A, 327-334.

Hootnick, D.R., Packard, Jr., D.S., Levinsohn, E.M., Lebowitz, M.R., Lubicky, J.P. (1984). The anatomy of a congenitally short limb with clubfoot and ectrodactyly. Teratology, 29, 155-164. doi:10.1002/tera.1420290202

Hootnick, D. (2014). Brief report embryonic arterial and skeletal dysgenesis: Syracuse Colloquium on Congenital Arterial and Skeletal Birth Defects September 28-29, 2013. Birth Defects Res A Clin Mol Teratol, 100, 789-791. http:/doi.org//10.1002/bdra.23253. 
SYNDROME OF LONG BONE DEFICIENCIES

Huda, S., Sangster, G., Pramanik, A., Sankararaman, S., Tice, H., Ibrahim, H. (2014). Hemimelia and absence of the peroneal artery. J Perinatol, 34, 156-158. doi: 10.1038/jp.2013.137

Koczewski, P., Shadi, M., Kotwicki, T., Tomaszewski, M., Korbel, K. (2013). Intermediate ray deficiency-a new type of lower limb hypoplasia. Skelet Radiol, 42, 377-383. doi: $10.1007 / \mathrm{s} 00256-012-1469-3$.

Koman, L.A., Meyer, L.C., Warren, F.H. (1982). Proximal femoral focal deficiency: a 50-year experience. Dev Med Child Neurol, 24, 344-355. doi:10.1111/j.1469-8749.1982.tb13627.x Kruger, L.M., Talbott, R.D. (1961). Amputation and prosthesis as definitive treatment in congenital absence of the fibula. J Bone Joint Surg Am, 43-A, 625-642. doi:10.2106/00004623196143050-00001

Lenz, W.D. (1969). Bone defects of the limbs - an overview. Birth Defects: Original Article Series $V, 1,6$.

Levinsohn, E.M., Hootnick, D.R., Packard, Jr., D.S. (1991). Consistent arterial abnormalities associated with a variety of congenital malformations of the human lower limb. Invest Radiol, 26, 364-373. doi:10.1097/00004424-199104000-00015

Lewin, S.O., Opitz, J.M. (1986). Fibular a/hypoplasia: review and documentation of the fibular developmental field. Am J Med Genet Suppl, 2, 215-238. doi:10.1002/ajmg.1320250626 Maroteaux, P., Le Merrer, M. (1997). Clinical approach still has an important role in constitutional bone diseases. J Pediatr Orthop B, 6, 1-6. doi:10.1097/01202412-19970100000001

Menelaus, MB. (1991). An attitude to the management of limb inequality. In: M.B. Manleaus (Ed). The Management of Limb Inequality. Edinburgh, Scotland: Churchill Livingstone. p.1-8. 
SYNDROME OF LONG BONE DEFICIENCIES

Ollerenshaw, R. (1925). Congenital defects of the long bones of the lower limb. J Bone Joint Surg Am, 7, 528-552.

O'Rahilly, R. (1951). Morphological patterns in limb deficiencies and duplications. Am J Anat, 89, 135-193. doi:10.1002/aja.1000890202

Packard Jr., D.S., Levinsohn, E.M., Hootnick, D.R. (1991). Teratological implications of soft tissue abnormalities found in human lower limbs with bony defects. In: Feinberg, R.N., Shererer, D.K., Auerbach, R. (Eds). Development of the Vascular System. Issues in Biomedicine. New York: Karger. p.157-169.

Packard Jr., D.S., Levinsohn, E.M., Hootnick, D.R. (1993). Most human lower limb malformations appear to result from postspecification insults. Prog Clin Biol Res, 383A, 417426.

Pappas, A.M. (1983). Congenital abnormalities of the femur and related lower extremity malformations: Classification and treatment. J Pediatr Orthop, 3, 45-60. doi:10.1097/01241398198302000-00009

Reyes, B.A., Birch, J.G., Hootnick, D.R., Cherkashin, A.M., Samchukov, M.L. (2017). The nature of foot ray deficiency in congenital fibular deficiency. J Pediatr Orthop, 37, 332-337. doi: 10.1097/BPO.0000000000000646

Rodriguez-Ramirez, A., Thacker, M.M., Becerra, L.C., Riddle, E.C., MacKenzie, W.G. (2010). Limb length discrepancy and congenital limb anomalies in fibular hemimelia. J Pediatr Orthop B, 19, 436-440. doi: 10.1097/BPB.0b013e32832d5d7d. 
SYNDROME OF LONG BONE DEFICIENCIES

Sarrafian, S.K., Kelikian, A.S. (2011). Angiology. In: Kelikian, A.S., (Ed). Sarrafian's Anatomy of the Foot and Ankle: Descriptive, Topographic, Functional. $3^{\text {rd }}$ Edition. Philadelphia:

Lippincott Williams \& Wilkins. p. 302-380.

Searle, C.P., Hildebrand, R.K., Lester, E.L., Caskey, P.M. (2004). Findings of fibular hemimelia syndrome with radiographically normal fibulae. J Pediatr Orthop B, 13, 184-188. doi:10.1097/01202412-200405000-00008

Senior, H. (1985). Development of the arteries. In: Clemente, C.D., (Ed). Gray's Anatomy. $13^{\text {th }}$ American Edition. Baltimore, MD: Williams \& Wilkins. p. 658.

Senior, H. (1919a). The development of the arteries of the human lower extremity. Am J Anat, 25, 54-95. doi:10.1002/aja.1000250105

Senior, H.D. (1919b). An interpretation of the recorded arterial anomalies of the human leg and foot. J Anat, 53, 130-171.

Song, K.M., Halliday, S.E., Little, D.G. (1997). The effect of limb-length discrepancy on gait. $J$ Bone Joint Surg Am, 79, 1690-1698. doi:10.2106/00004623-199711000-00011

Spranger, J., Benirschke, K., Hall, J., Lenz, W., Lowry, R., Opitz, J., Pinsky, L., Schwarzacher, H., Smith, D. (1982). Errors of morphogenesis: concepts and terms: recommendations of an international working group. J Pediatr, 100, 160-165. doi:10.1016/s0022-3476(82)80261-8 Stevens, P.M., Arms, D. (2000). Postaxial hypoplasia of the lower extremity. J Pediatr Orthop, 20, 166-172. doi:10.1097/01241398-200003000-00007

Tabin, C., Wolpert, L. (2007). Rethinking the proximodistal axis of the vertebrate limb in the molecular era. Genes Dev, 21, 1433-1442. doi:10.1101/gad.1547407 
SYNDROME OF LONG BONE DEFICIENCIES

Thompson, T.C., Straub, L.R., Arnold, W.D. (1957). Congenital absence of the fibula. J Bone

Joint Surg Am, 39-A, 1229-1237. doi:10.2106/00004623-195739060-00001

Vargesson, N., Hootnick, D.R. (2017). Arterial dysgenesis and limb defects: Clinical and experimental examples. Reprod Toxicol, 70, 21-29. doi: 10.1016/j.reprotox.2016.10.005

Wagstaffe, W.W. (1873). Peculiar malformation of the leg and foot. J Anat Physiol, 7, 156-160.

Zuniga, A., Zeller, R., Probst, S. (2012). The molecular basis of human congenital limb malformations. Wiley Interdiscip Rev Dev Biol, 1, 803-22. doi:10.1002/wdev.59

Zuniga, A. (2015). Next generation limb development and evolution: old questions, new perspectives. Development, 142, 3810-3820. doi:10.1242/dev.125757 